* Corresponding author

Phone +421556022716

E-mail address:miroslav.badida@tuke.sk

(prof. Dr. h. c. Ing. Miroslav Badida, PhD.)

Article information

Article history: AMS-Volume16-No.2-00159-12

Received 12 February 2012

Accepted 4 April 2012

\section{System of Collecting and Recycling of the Portable Batteries and Accumulators in Slovakia}

\author{
Králiková Ružena a , Badida Miroslav a*, Andrejiová Miriam b \\ ${ }^{a}$ Department of Environmental, Faculty of Mechanical Engineering, P. Komenského 5, 04200 Košice, Slovak Republic \\ ${ }^{b}$ Department of Applied Mathematics and Informatics, Faculty of Mechanical Engineering, Letná 9, 04200 Košice, Slovak Republic
}

\section{BIOGRAPHICAL NOTES}

Ružena Králiková, doc. Ing. PhD. received M.S. degree in mechanical engineering form Technical University of Košice, Slovakia in 1980 and PhD. degree in 1996. She is an associated profesor of the Department of Environmental Sciences at the Faculty of Mechanical Engineering at the Technical University of Košice, Slovakia from 2001. Her researche interests include environmental monitoring, engineering and management, working environment, especially lighting and microclimate conditions of environment. She has autored of the monography, 6 textbooks and more than 100 journal and conference papers on this topics.

Miroslav Badida, Dr.h.c. prof. Ing. PhD. He is a graduate of Mechanical Faculty of Technical University of Košice. His scientific and research work focuses on the field of environmental engineering. An accent is put on the issue of environmental management systems, ecologization of products and their production and life cycle analysis of products. Lately his attention is paid on research in the field of physical factors of working and living environment.

Miriam Andrejiová, RNDr. PhD. graduated in 1997 at Faculty of Science at Pavol Jozef Šafárik University in Košice in field of mathematics and physics. She obtained her postgraduate degrees in "Theory of Physics Teaching” at Faculty of Science at University of Pavol Jozef Šafárik in Košice. Since 1998 she has worked as assistant and special assistant at Department of Applied Mathematics and Informatics at Faculty of Mechanical Engineering at Technical University in Košice.

\section{KEY WORDS}

Recycling, collecting, accumulators, portable batteries.

\section{ABSTRACT}

The contribution deals with problems of collection and recycling of portable battery and accumulators. Analyzed knowledge, conclusions and methods was summarized to suggest methodology of collection optimization of used transferable germs and accumulators. This methodology for optimal draft to effective settling of appropriate system of collection, processing, evaluation and recyclation of used portable batteries and accumulators was created according to current legislation.

\section{Introduction}

The current state in the area of collecting and recycling batteries is complicated. This situation is caused mainly by charging the battery manufacturers, while no indices and anticipations for systemic collection of used batteries from distribution spots, 
in terms of the waste act, are not being fulfilled. The same situation is also in the case of recycling, storage and disposal of these used batteries. This condition is unfavorable not only from the state's point of view and its attitude towards the EU legislation and its fulfilling, but also for manufacturers or importers, who are directly responsible for putting the directive in practice. Therefore it is vital to search for the means of making the process of collecting more effective and find the solutions to this problem.

\section{Legislative framework}

Considering the European legislative - Directive 2006/66/EC, all the member states must reach a certain level of backwards collecting, processing and recycling of portable batteries. According to the directive, the level of collecting and subsequent recycling of used portable batteries and accumulators in the EU member states should reach the target of $25 \%$ by 2012. This share should be at least $45 \%$ by 2016. At the same time, the new directive forbids selling of batteries and accumulators which contain more than $0,0005 \%$ of mercury and portable batteries which contain more than $0,002 \%$ of cadmium. The forbiddance doesn't include the portable batteries used in emergency and alarm systems, medical appliances and wireless electronic appliances.

The target level of $45 \%$ of collecting is currently being reached only in Belgium and Switzerland, however very close to this number are the collective organizations in Austria, Germany and Netherland. Seeing that it is necessary to create good conditions for successful fulfillment of mentioned goals of waste management in this particular area - used portable batteries and accumulators.

The directive assumes that financing of the costs of collecting, recycling and processing of all batteries must be secured by the manufacturers and importers of batteries in the Slovak Republic (SR). The separated collecting and recycling of industrial and automobile accumulators can be financed from the very good revenues gained by selling the obtained metals. Different situation is in the case of portable batteries, where the costs of collecting and processing significantly exceed the returns from recycling. The directive sets the compulsory recycling of all collected batteries and accumulators, which subsequently have to be materially capitalized.

\section{General information}

Each year are imported to Slovakia about 11001400 tones of portable batteries and accumulators. This represents an enormous burden for environment, especially when amount that big isn't being suitably processed. Issue of this kind of waste is very current topic from several points of view: environmental, economic, law and technical/technological.

Collecting itself is a significantly complicated phase of the whole manipulation process with used portable batteries and accumulators. This particular phase still isn't completely solved, even in the countries which organize the collecting of used batteries for more than 10 years. The consequence of relatively low share of collected used batteries is the fact that many portable batteries finally end in an ordinary municipal waste. Possible material potential is being destroyed on dumping places and in incinerator plants. This material potential could be used to reach savings in drawing from primary natural resources etc. It is therefore necessary to collect and recycle as much used portable batteries and accumulators as possible. It is generally estimated, that maximal possible extent of recycling is approximately $80-85 \%$, because it is not possible to indentify the differential percentage of collected used portable batteries and accumulators, concerning their chemical composition. In countries where collecting of portable batteries is organized via collecting spots together with electro-waste, the level of collected amount is considered to be low, approximately $30 \%$ from the total presence in the particular country. Only the returned batteries can be collected and only those collected ones could be then sorted and recycled. The essential of this system is complexity beginning at the collecting stage and ending in the industrial usage of gained materials from used portable batteries and accumulators. Manipulating with used portable batteries and accumulators is a serious problem for every single state which won't be able to fulfill the conditions of the new European legislative, as well as for manufacturers and importers who are fully responsible for fulfillment of this legislative.

The act of Ministry of environment No. 386/2009 Slovak Republic about wastes is an implantation of 
the requirements set in the directive of European parliament and Council 2006/66/ES about batteries and accumulators and about waste batteries and accumulators.

The current situation is mostly about charging the manufacturers. However, indices and assumptions for systemic collecting of used portable batteries are not being consistently fulfilled, especially in the case of collecting spots defined by law. We are talking mainly about distribution places defined by the mentioned law. These are the places where the new portable batteries and accumulators are being sold. Recycling, storage and material valuation or disposal are also defined and lacking practical effect. The sole recipient of the fees is currently the Recycling Fund of the Slovak Republic (RF), which:

- returns the fees for the collected and recycled batteries backwards or

- may grant the donations for projects concerning collecting and recycling, however there is no legal claim for these donations.

Based on the information from the European parliament, as well as considering the development in this area, the REBAT (Slovak association for recycling batteries) association was established in 2006. In cooperation with an international organization EPBA (European Portable Battery Association), the association aims to work out the strategic plans for reaching the maximum effect in facilitating backwards-collecting of the used batteries and their disposal or recycling in collaboration with authorized processor. The European Portable Battery Association is the leading organisation representing the interests of primary and rechargeable portable battery manufacturers, those industries using portable batteries in their products and distributors of portable batteries active within the European Union, and beyond. According to data association of REBAT, in 2009 started running a promisingly system for the collection and recycling of waste batteries and accumulators by the firms MACH TRADE and INSA, which are among the largest processors of batteries in Slovakia. Back collection also started realizes the most importers of batteries, firms Varta, Emos, Energizer, etc. In 2010, the company MACH TRADE assessed and collected more than 559 tons of portable batteries. It is more than $25 \%$ of the total imported to Slovakia, which fulfilled its commitment to the EU.

\section{Trends and development of consumption}

As it was mentioned earlier, the waste market with used portable batteries in SR currently represents amount of 1100-1400 tons per calendar year. This number is crucial for setting the right collecting, processing and recycling capacities. Its size determines the possibility of creation as well as consequent usage of such capacities in SR or moving the collected and sorted used portable batteries and accumulators to recycling facility in abroad, with preference of the EU countries. The size of this waste market is currently being made of average consumption of portable batteries per SR citizen in amount of 4,8 batteries per year. Just for contrast and comparison of situation within EU we would like to mention, that the above indicator in the EU founding countries is in the range of 10-12 batteries per citizen per year.

Aforesaid consumption consists of the two main categories, which are:

\section{Primary batteries, mostly divided into: -zinc - chloride batteries -alkaline batteries}

-lithium batteries, these however still represent only minimal share in the segment of primary batteries

\section{Secondary batteries (accumulators).}

Unit as well as weight proportion between the shares of primary and secondary batteries speak clearly about the dominance of primary batteries, in the rate $97 \%$ to $3 \%$. Based on this reality, the trend of development and consumption of the primary portable batteries in the recent years is a vital parameter for us. This parameter would identify potential running out of the development of consumption in the western European countries.

\section{Forecasting using exponential smoothing method}

The oldest method of time series modelling is the decomposition of time series. This method assumes that the time series can be divided into several independent components. Classical time series decomposition distinguishes four basic components: trend component $T_{t}$ (or secular component), the seasonal component $S_{t^{\prime}}$ the cyclical component $C_{t}$ and irregular $I_{t}$ (or residual component) component. [10,11]

The trend component is a major long-term development trend indicator value of the analysed time 
series and can occur in a linear or nonlinear form, it may be increasing, decreasing or constant. The seasonal component of a time series is defined as the regular periodic fluctuations around the trend line in one year or less. The cyclical component is defined as the fluctuations around a trend with irregular periods longer than one year. The irregular component is unpredictable. Every time series has some unpredictable component that makes it a random variable.

These four components may be combined in different ways. It is usually assumed that they are multiplied or added:

-additive model assumes that all the components of the time series are independent of one another

$Y_{t}=T_{t}+S_{t}+C_{t}+I_{t}$

-multiplicative model assumes that all the four components are due to different cause but they are not necessarily independent

$Y_{t}=T_{t} \cdot S_{t} \cdot C_{t} \cdot I_{t}$

where $Y_{t}$ is observed value at time $t$.

There are several methods for selection of an appropriate model of the trend. To describe the trend component we can use analytical methods (resp. non adaptive methods). These methods try to describe the trend and an appropriate mathematical function based on the assumption that the model throughout the observed period changes. Adaptive methods steadily (adapting) adapt to changes in the nature of the trend. The most famous adaptive methods include moving averages and exponential smoothing method. Other adaptive methods include the Box-Jenkins methodology.

Adaptive exponential smoothing methods allow a smoothing parameter to change over time, in order to adapt to changes in the characteristics of the time series. Exponential smoothing is a simple and pragmatic approach to forecasting, where by the forecast is constructed from an exponentially weighted average of past observations.

This method is based on all previous observations, and their weight decreases towards the past, according to an exponential function. The older observation is the impact on its future value is smaller, and gives it an exponentially decreasing weight.

Pegels (1969) proposed taxonomy of exponen- tial smoothing methods where each method has a trend component and a seasonal component. The all exponential smoothing methods are given in the following Table $1[8,9]$.

Table 1: Models of exponential smoothing method.

\begin{tabular}{llll}
$\begin{array}{l}\text { Trend } \\
\text { component }\end{array}$ & & \multicolumn{2}{c}{ Seasonal component } \\
& N (none) & A (additive) & M (multiplicative) \\
N (none) & NN & NA & NM \\
A (additive) & AN & AA & AM \\
M (multiplicative) & MN & MA & MM \\
D (damped) & DN & DA & DM
\end{tabular}

NN model describes the simple exponential smoothing method. AN model is Holt's exponential smoothing and the models of AA and AM are known as Holt-Winters exponential smoothing method. There are two possible models for each of the twelve methods: models with additive and multiplicative errors.

All twelve exponential smoothing methods can be written by using the following form:

$$
\begin{aligned}
& l_{t}=\alpha P_{t}+(1-\alpha) Q_{t}, \\
& b_{t}=\beta R_{t}+(\Phi-\beta) b_{t-1}, \\
& s_{t}=\gamma T_{t}+(1-\gamma) s_{t-m},
\end{aligned}
$$

where $l_{t}$ denotes the series level at time $t, b_{t}$ the trend (slope) at time $t, s_{t}$ the seasonal component of the series at time $t, m$ denotes the number of seasons in a year. The values $P_{t}, Q_{t}, R_{t}$ and $T_{t}$ depended on the type of the method of smoothing. The Constants $\alpha, \beta, \gamma$ s are from interval $(0,1)$. The constant $\Phi$ are for damped trend form interval $\beta<$ $\Phi<\mathbf{1}$, in other cases is equal to 1 .

The formulas for calculations the values $P_{t}, Q_{t}$, $R_{t}, T_{t}$ and points forecast for Holt's exponential smoothing (AN model) and Holt-Winters' exponential smoothing method (model AA and AM) are in the Table 2. The observed value in time $t$ is denoted by $Y$, forecast for $\mathrm{h}$-periods is denoted by $F_{t+h}$.

For each method there are two models: model with additive and model with multiplicative errors. The model with additive errors is written as $Y_{t}=\mu_{t}$ $+\varepsilon_{t}$, the model with multiplicative errors is written as $Y_{t}=\mu_{t}+\mu_{t} \varepsilon_{t}=\left(1+\varepsilon_{t}\right) \mu_{t}$.

Forecasting using the exponential smoothing 
methods is discussed more extensively in the work of Hyndma [8]

For this research, the sale results of a distribution company, which operates in the whole Slovak Republic, were used. This company represents approximately $15 \%$ of the whole market with portable batteries and accumulators in SR, which makes our data exceptionally predicative. This predicative ability is supported by stable market shares of the distributed brands in SR, documented by the AC NIELSEN company, which in the long term monitors the mentioned segment.

For setting the trend of consumption, the sale data from years 2003 - 2010 have been used. As a base data we used the sale results from the year 2003 , to which we compared sale results in the fol- lowing years through the coefficient of growth

We have to identify the type and model of time series and forecasts to determine a period of 36 months with using the open source $\mathrm{R}$ software package (package "forecast"). The output from this software is the type of exponential model in the form of ETS (Error, Trend, and Seasonal).

The analysis of output from the R package indicates that the most advantageous model is model without trend with additive seasonal component and multiplicative errors (MNA model). In this case a balancing constant $\alpha$ is equal to 0.1156 and the second constant $\gamma$ is equal to 0.0001 . The Figure 1 shows a graphical representation of empirical values together with the forecast values and the 80\% and $90 \%$ confidence intervals.

Table 2: The formulas for AN, AA and AM model.

\begin{tabular}{|c|l|l|l|}
\hline \multirow{2}{*}{$\begin{array}{c}\text { Trend } \\
\text { component }\end{array}$} & \multicolumn{3}{|c|}{ Seasonal component } \\
\cline { 2 - 4 } & \multicolumn{1}{|c|}{$\mathbf{N}$ (none) } & \multicolumn{1}{|c|}{ A (additive) } & \multicolumn{1}{c|}{ M (multiplicative) } \\
\hline \multirow{4}{*}{ A (additive) } & $P_{t}=Y_{t}$ & $P_{t}=Y_{t}-S_{t-m}$ & $P_{t}=Y_{t} / s_{t-m}$ \\
\cline { 2 - 4 } & $Q_{t}=l_{t-1}+b_{t-1}$ & $Q_{t}=l_{t-1}+b_{t-1}$ & $Q_{t}=l_{t-1}+b_{t-1}$ \\
\cline { 2 - 4 } & $R_{t}=l_{t}-l_{t-1}$ & $R_{t}=l_{t}-l_{t-1}$ & $R_{t}=l_{t}-l_{t-1}$ \\
\cline { 2 - 4 } & & $T_{t}=Y_{t}-Q_{t}$ & $T_{t}=Y_{t} / Q_{t}$ \\
\cline { 2 - 4 } & $F_{t+h}=l_{t}+h b_{t}$ & $F_{t+h}=l_{t}+h b_{t}+s_{t+h-m}$ & $F_{t+h}=\left(l_{t}+h b_{t}\right) s_{t+h-m}$ \\
\hline
\end{tabular}

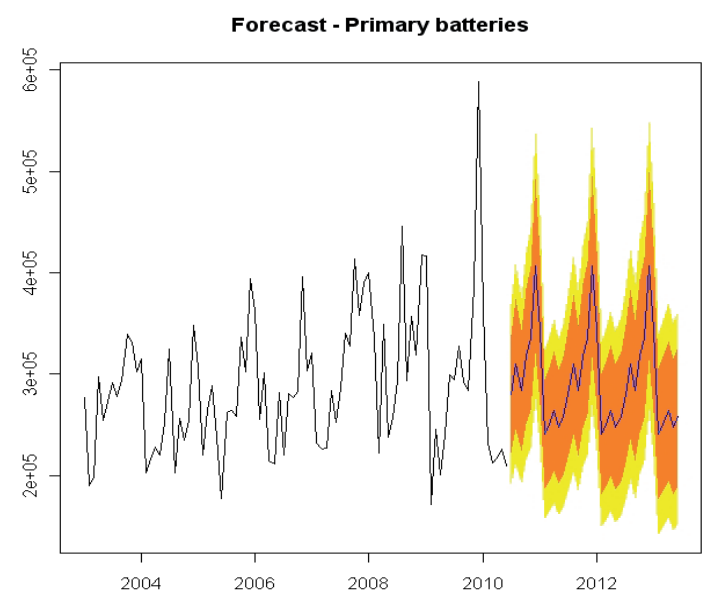

Fig. 1: Trend and forecast of consumption of the primary batteries in $S R$.

Primary batteries are, as a whole, characterized by various size types of these batteries. As the carrying types in this category the following size types could be considered: AAA, AA, C, D, 9V. From the creation of the consumption trend point of view, it is interesting to look at the mentioned tendency through the type marking. This trend is, for comparability, compared also to the base year 2003 through the coefficient of growth or decline in particular following year. This is graphically shown in the Figure 2.

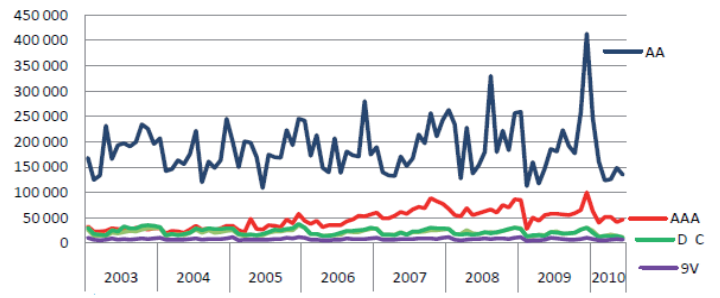

Fig. 2: Trend of consumption of the primary batteries in SR based on the particular types.

As it is obvious from the Figure 2, the growth of overall consumption of the primary batteries was 
effected mainly by the growth of the AAA type, which is commonly used in modern appliances and which in fact represents the smallest portable primary unit from the mentioned basic group. Growth in the monitored term was more than double. Concerning the initial starting position of the AAA type in 2003 is, however, the impact on the overall trend of consumption of the primary batteries smaller than expected. The trend of consumption is negatively effected by the declines in consumption of the so called big batteries (types ( and D), which are caused by the miniaturization of the electronic appliances and subsequent demand for minimization of the portable source of energy (represented by primary battery) as well. The trend-stable graph with slight trend growth is in the case of batteries with the type marking AA and $9 \mathrm{~V}$, which did not record a significant deviation in the whole length of the monitored term.

\section{Discussion}

Potential risk for the environment, resulting from the great amount of used primary batteries represents a challenge for manufacturers, distributors, final consumers of batteries and most of all for those subjects, which are directly involved in collecting, processing and recycling of the used portable batteries and accumulators. Only the returned batteries can be collected, and only collected batteries can be then sorted and recycled. Evaluating of the primary and secondary portable batteries in Slovak Republic still lags behind the advanced European countries. The basis of an effective system is complexity, since the collecting till the final industrial usage of gained materials from used portable batteries and accumulators. Significantly high effectiveness is a matter of great interest of manufacturers and importers of the portable batteries in SR, because its cost greatly influences the process of price-making of the new portable batteries.

Analyzed knowledge, conclusions and methods was summarized to suggest methodology of collection optimization of used transferable germs and accumulators, see Figure 3. The most effective system will be successfully built by using their distribution capabilities, within the system of sellingcollecting. This model presents optimal draft to effective settling of appropriate system of collection, processing, evaluation and recyclation of used portable batteries and accumulators regarding to cur- rent legislation. If there is a change in legislation, can be corrected in the process parameters of the additional definitions, which does not affect the algorithm, which was designed in resolving research project at the Department of environmentalistics.

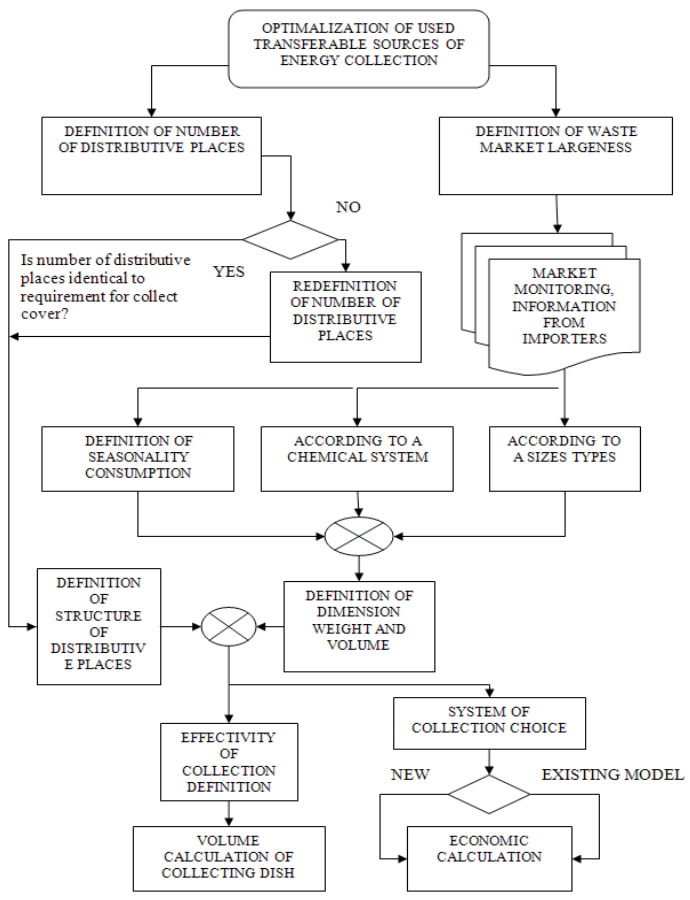

Fig. 3: Structured diagram of methodology of collection optimization of used transferable germs and accumulators.

\section{Conclusion}

Considering the trend of consumption development of the portable primary batteries and accumulators in SR, it is not possible to anticipate significantly rapid growth of the waste market in this area. On the contrary, it is possible to expect balanced, slightly increasing unit consumption, which is the input assumption for the consequent solution and optimization of the collecting, processing and recycling capacities (concerning the measure of technical and logistic facilitating). It will be necessary to minutely evaluate the particular trends which influence the unit consumption, because the increase of the unit consumption of the smallest types and decrease of consumption of the bigest types could eventually cause dimensional decrease of the waste market size on the base of weight units. 


\section{Acknowledgements}

This contribution was worked - out frame within the frame project No 032TUKE-4/2012 „ICT aided new forms of learning and increasing the efficiency of education for environmental study programs".

\section{References}

[1] Hohn, B., Modern Gear Calculation, Proceedings of the International Conference on Gears, Munich 2002, VDI-Berichte, pp 23-43

[2] Council Directive 91/157/EEC of 18 March 1991 on batteries and accumulators containing certain dange-rous substances, Official Journal L 078, 26/03/1991

[3] Legislative resolution on the proposal for a decision of the 91/157/EEC (5694/5/2005-C6-0268/2005-2003/0282(COD)), European Parliament, Brussels.

[4] Commission directive 98/101/EC adapting to technical progress Council Directive 91/157/EEC on batteries and accumulators containing certain dangerous substances

[5] Directive 2006/66/EC on batteries and accumulators and waste batteries and accumulators as regards placing batteries and accumulators on the market

[6] Slovak directive No 386/2009 SR amending and supplementing no. 223/2001 about waste

[7] Pegels, C.C.: Exponential forecasting: some new variations. Management Science, 12, pp 311-315

[8] Hyndman, R.J. - Koehler, A.B. - Snyder, R.D. - Grose, S.: A state space framework for automatic forecasting using exponential smoothing methods. International Journal of forecasting 18 (2002), pp 439-454

[9] Hyndman. R.J.: Time series and forecasting in R. Monash University, 2008. In: http://wwwmaths.anu.edu.au

[10] Rublíková, E. Analýza časových radov. Bratislava: Iura Edition, 2007. 207 p.

[11] Hudec, O. a kol.: Štatistické metódy v ekonomických vedách. Košice: Elfa, s.r.o.,2007. 196 p. 